\title{
Impact of Media Multitasking on Work Engagement Under the Background of the Internet Based on Resource Limitation Theory
}

\author{
Zhengjie $\mathrm{Xu}^{1, *}$ and Yang Zhao ${ }^{1}$ \\ ${ }^{1}$ School of Economics and Management, Beijing Jiaotong University, Beijing, 100044, China \\ *Corresponding author. Email: 20120712@bjtu.edu.cn
}

\begin{abstract}
With the rapid development of science and technology, the media is constantly updated in the current information age, and it increasingly affects people's daily lives. This paper attempts to explore the impact of media multitasking on employees' work engagement. Based on the survey of employees in different industries, different age groups and different types of units, 202 valid questionnaires were collected, and the media multitasking index was calculated to study that modern enterprise employees spend on the media every day. According to the ranking of media usage time, the three longest media activities are: replying to instant message, using office software for work or study, and listening to music. The results of empirical research show that media multitasking has a negative impact on work engagement. Therefore, enterprises should take measures to control employees' media multitasking behavior.
\end{abstract}

Keywords: Media multitasking; work engagement; attention resources; resource limitation theory

\section{INTRODUCTION}

In an increasingly saturated media environment, media multitasking in which one person uses multiple items or content streams at the same time is becoming more and more common[1], especially among young people[2]. According to the "Statistical Report on China's Internet Development Status" released by the China Internet Network Information Center, as of December 2020, the number of Internet users in China has reached 940 million, accounting for $1 / 5$ of the global Internet users; the number of mobile Internet users has reached 986 million. From the perspective of age level, netizens between the ages of 2029 and 30-39 account for 38.39\%. They are not only the main group of netizens and media multitasking behavior, but also the main force of enterprise development.

With the development of science and technology and the advent of the mobile Internet era, employees' media multitasking behavior has become a general trend. The use of media multitasking to handle work, social, and entertainment activities has become a common phenomenon, and scholars have already responded to it. However, at the same time, with the popularity of the Internet and various media devices, readers' attention has become more and more distracted, showing a typical shallow state: shallow reading, shallow trying, shallow receiving and shallow sharing. So, for companies, does the media multitasking behavior of employees have a certain impact on their work engagement? This is the purpose of this article.

\section{LITERATURE REVIEW}

\subsection{Media Multitasking}

Media multitasking is usually defined as "performing two or more tasks at the same time, one of which involves media use"[3]. It includes three categories: (a) Media and non-media tasks, such as watching TV and doing homework[4]; (b) Two different media, such as watching TV and using the Internet[5]; (c) Two tasks on a single media, such as sending e-mail and browsing web pages simultaneously on a computer[6]. Multitasking is usually defined as switching or performing two tasks at the same time. When one of the tasks is a media usage task, it is media multitasking[3]. To sum up, when defining media multitasking, scholars mainly focus on two aspects: simultaneity and multitasking.

Existing research results show that multi task processing can affect individual cognitive ability[7][8]. Heavy media multi task processors perform worse in task switching ability test[1]. Media multitasking behavior in learning context has both negative and positive effects[9]. The effect of online learning depends on the experience of media multitasking and the frequency of information processing[10].

This paper uses Media Use Questionnaire to measure the Media Multitasking Index (MMI) and judge the tendency of individual media multitasking[11][12]. The MMI is calculated by the following formula. The scoring method 
is: "always $=1$ ", "sometimes $=0.67$ ", "occasionally $=$ $0.33 "$ and "never $=0 "$.

$$
M M I=\sum_{\mathrm{i}=1}^{\mathrm{i}=\mathrm{n}} \frac{M_{\mathrm{i}} \times H_{\mathrm{i}}}{H_{\text {hotal }}}
$$

$\mathrm{M}_{\mathrm{i}}$ refers to the number of activities carried out by one major media at the same time with other media, $\mathrm{H}_{\mathrm{i}}$ refers to the time spent in a certain media activity per day, and $\mathrm{H}_{\text {total }}$ refers to the time of all major media activities per day.

\subsection{Work Engagement}

At present, there are two main ways to study work engagement: one is to study work engagement as the opposite of job burnout; the other is to study work engagement and job burnout as different concepts [13]. In this paper, the definition of work engagement adopts schaufeli's definition recognized by academic circles, which is work engagement is a positive, active, stable and continuous state of employees' involvement in work, including three dimensions of vigor, dedication and absorption [14].

\section{RESEARCH HYPOTHESIS}

Kahneman put forward the resource limitation theory in his book attention and effort in 1973, which means attention is a very limited psychological resource. When an individual operates two or more tasks at the same time, he needs to allocate psychological resources according to the needs of the task, and the amount of resources allocated will not exceed the total amount of psychological resources. In the process of work, if the media multitasking index is too high, it will affect the staff's attention resources and work engagement. Therefore, media multitasking behavior may occupy employees' attention and other cognitive resources, which has a negative impact on work engagement. Based on the above theory and existing research, this study assumes that:

H1: there is a negative correlation between media multitasking and employees' work engagement;

Hla: there is a negative correlation between media multitasking and employees' work engagement;

Hlb: there is a negative correlation between media multitasking and employee dedication;

H1c: there is a negative correlation between media multitasking and employee's work engagement.

\section{RESEARCH DESIGN AND RESULTS}

\subsection{Samples and Data}

The sample data of this study comes from the questionnaire survey. In order to improve the representativeness of the sample, this survey selected employees from different nature, different locations and different industries as samples. In this study, 202 valid questionnaires were obtained, and the effective recovery rate was $81.12 \%$.

According to the ranking of daily media usage, the three longest media activities among the 202 respondents were instant messaging, office software and music. The three activities with the shortest time are listening to audio books, playing video games and using non-social networking sites. The average time of using media was 12.89 hours per day. Sending and receiving instant messages, such as WeChat, QQ messages, text messages, emails, etc., takes the most time, with an average cost of $2.09 \mathrm{~h}$ per day.

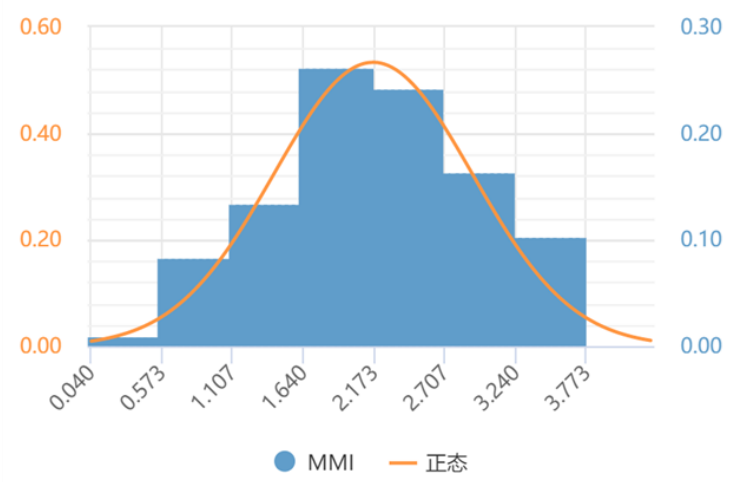

Figure 1. Index Histogram of MMI

Through the statistics and calculation of media multitasking index of 202 samples, the maximum value of media multitasking index (MMI) is 3.72 , the minimum value is 0.52 , and the distribution interval is $2.16 \pm 1.64$, normal distribution. The results of other domestic scholars on the distribution interval of MMI is $3.2 \pm 1.4[11]$; $2.71 \pm$ 1.34[15]. The statistical results of this paper are similar to those of previous studies, which shows that it has a certain degree of credibility.

The results show that when using other computer software or mobile applications, such as reader, Word, Excel, etc., to work or study, the media multitasking index is the highest, which is 2.64; The media multitasking index (MMI) was 2.579 and 2.191 respectively. When watching TV, movies, dramas, online or offline videos, the MMI value of media multitasking index was the lowest, only 1.526. 
Table 1. Daily Time Proportion of Media Activities(N=202)

\begin{tabular}{lcc}
\hline \multicolumn{1}{c}{ Media Type } & $\begin{array}{c}\text { Hour } \\
\text { /Day }\end{array}$ & $\begin{array}{c}\text { Proportion } \\
\text { (\%) }\end{array}$ \\
\hline $\begin{array}{l}\text { 1. Call, voice or video chat } \\
\text { 2. Listen to audiobooks, } \\
\text { Internet radio, etc. }\end{array}$ & 1.27 & 5.30 \\
\hline $\begin{array}{l}\text { 3. Send and receive instant } \\
\text { messages, such as WeChat, QQ } \\
\text { messages, emails, etc. }\end{array}$ & 2.09 & 4.15 \\
\hline $\begin{array}{l}\text { 4. Use social networking sites, } \\
\text { such as Weibo, Zhihu, WeChat } \\
\text { official account, etc. }\end{array}$ & 1.77 & 7.36 \\
\hline $\begin{array}{l}\text { 5. Playing electronic games, } \\
\text { such as competitive games, } \\
\text { puzzle games, etc. }\end{array}$ & 1.07 & 4.48 \\
\hline $\begin{array}{l}\text { 6. Use non-social networking } \\
\text { sites, such as news, consulting, } \\
\text { encyclopedias, etc. }\end{array}$ & 1.23 & 5.14 \\
\hline $\begin{array}{l}\text { 7. Watch TV, movies, web } \\
\text { dramas, online or offline } \\
\text { videos, etc. }\end{array}$ & 1.25 & 5.22 \\
\hline $\begin{array}{l}\text { 8. Use other computer software } \\
\text { or mobile phone applications } \\
\text { such as reader, Word, Excel, } \\
\text { etc. }\end{array}$ & 1.87 & 7.80 \\
\hline $\begin{array}{l}\text { 9. Listen to music, such as } \\
\text { NetEase Cloud Music, QQ } \\
\text { Music, etc. }\end{array}$ & 1.34 & 5.57 \\
\hline & 12.89 & 53.71 \\
\hline
\end{tabular}

\subsection{Reliability and Validity Testing}

The questionnaire in this study adopts the Utrecht Work Engagement Scale (UWES) compiled by Schaufeli ${ }^{[14]}$. After analysis, the reliability coefficient value of the work input scale is 0.927 , the commonness value is greater than 0.4 , and the KMO value is 0.951 , indicating that the data is highly valid. Thus, it proves that this scale has good validity and can be used for further analysis.

Table 2. Reliability Testing

\begin{tabular}{cccc}
\hline Dimension & Code & CITC & Cronbach $\boldsymbol{\alpha}$ \\
\hline \multirow{4}{*}{ Vigor } & A1 & 0.756 & \\
& A2 & 0.754 & \\
& A3 & 0.711 & \\
Dedication & A4 & 0.696 & \\
& A5 & 0.722 & 0.927 \\
& A6 & 0.699 & \\
Absorption & A7 & 0.777 & \\
& A8 & 0.754 & \\
& A9 & 0.742 & \\
\hline
\end{tabular}

Table 3. Validity Testing

\begin{tabular}{cccccc}
\hline \multirow{2}{*}{ Dimension } & \multicolumn{6}{c}{ Factor Loading Factor } & Common \\
& & $\boldsymbol{F 1}$ & $\boldsymbol{F ~ 2}$ & $\boldsymbol{F 3}$ & -ality \\
\hline \multirow{4}{*}{ Vigor } & B1 & 0.411 & 0.634 & 0.491 & 0.74 \\
& B2 & 0.77 & 0.42 & 0.474 & 0.782 \\
& B3 & 0.445 & 0.648 & 0.444 & 0.677 \\
& B4 & 0.482 & 0.803 & 0.452 & 0.787 \\
Dedication & B5 & 0.763 & 0.402 & 0.544 & 0.765 \\
& B6 & 0.463 & 0.451 & 0.856 & 0.865 \\
& B7 & 0.667 & 0.55 & 0.497 & 0.725 \\
Absorption & B8 & 0.421 & 0.471 & 0.633 & 0.715 \\
& B9 & 0.592 & 0.549 & 0.534 & 0.66 \\
KMO & & & 0.951 & & - \\
$p$ & & 0 & & & - \\
\hline
\end{tabular}

\subsection{Correlation Analysis}

From Table 4, we can see that there is a significant negative correlation between the media multitasking index (MMI) and work engagement $(\mathrm{r}=-0.923, \mathrm{p}<0.01)$;

There is a significant negative correlation between MMI and vigor $(\mathrm{r}=-0.892, \mathrm{p}<0.01)$;

There is a significant negative correlation between MMI and dedication $(\mathrm{r}=-0.892, \mathrm{p}<0.01)$;

There is a significant negative correlation between MMI and absorption $(r=-0.877, \mathrm{p}<0.01)$.

Table 4. Correlation Analysis

\begin{tabular}{crrrrr}
\hline & MMI & W E & V & D & A \\
\hline MMI & 1 & & & & \\
Work & $.923 * *$ & 1 & & & \\
Engagement & & & & & \\
Vigor & $.892^{* *}$ & $.949 * *$ & 1 & & \\
Dedication & $.844 * *$ & $.936 * *$ & $.839 * *$ & 1 & \\
Absorption & $.877 * *$ & $.948^{* *}$ & $.852^{* *}$ & $.823 * *$ & 1 \\
\hline \multicolumn{5}{c}{} \\
& & & & $* * \mathrm{p}<0.05, * \mathrm{p}<0.1$
\end{tabular}

\subsection{Regression Analysis}

The media multitasking index (MMI) was used as the independent variable, and the work engagement was used as the dependent variable, and linear regression analysis was performed.

The R-squared value of the model is 0.853 , and the regression coefficient of MMI is -0.844 ( $\mathrm{t}=-31.692$, $\mathrm{p}=0.000<0.01)$, indicating that the media multitasking behavior index will have a significant negative impact on work engagement.

However, gender, age, highest degree of education, nature of work unit, position level, and working years do not affect work engagement. 
Table 5. Regression Result

\begin{tabular}{cccc}
\hline \multirow{2}{*}{ Variable } & \multicolumn{3}{c}{ MMI } \\
\cline { 2 - 4 } & Vigor & Dedication & Absorption \\
\hline Beta & -0.892 & -0.844 & -0.877 \\
$t$ & -27.965 & -22.25 & -25.837 \\
$p$ & $0.000^{* *}$ & 0.712 & $0.000^{* *}$ \\
$R^{2}$ & 0.796 & 0.712 & 0.769 \\
$R^{2} a$ & 0.795 & 0.711 & 0.768 \\
$F$ & 782.017 & 495.047 & 667.554 \\
& $\left(0.000^{* *}\right)$ & $\left(0.000^{* *}\right)$ & $\left(0.000^{* *}\right)$ \\
\hline & & & $* * \mathrm{p}<0.05, * \mathrm{p}<0.1$
\end{tabular}

\section{DISCUSSION}

This study uses online questionnaires to conduct surveys. Therefore, the group of respondents may often participate in network activities and have electronic equipment. There is insufficient research on groups with a low degree of media. In addition, this article only discusses the correlation between independent variables and dependent variables, the mechanism of which is not clear; and there is insufficient research on boundary conditions.

Therefore, in future research, the scope and number of sample surveys can be expanded to further verify the relationship between media multitasking and work input, and improve the accuracy of the research results; secondly, use empirical research methods to make the research more powerful Universal applicability; Finally, the study of the mechanism of action between media multitasking and work input makes the research results more guiding significance.

\section{CONCLUSION}

Through the above empirical research, the hypotheses of this paper have been verified. Media multitasking has a significant negative impact on work engagement and its three dimensions: vigor, dedication, and absorption. Therefore, enterprises should refer to the following management suggestions during their operations:

First, enterprises should try to reduce employees' media multitasking behavior during the work time and improve their work concentration and efficiency.

Any task will occupy employees' cognitive resources, and when the work is a complex task, more energy and energy are required. Therefore, in the work process, the high degree of media multitasking will inevitably affect employees' cognitive resources and reduce work engagement. For example, frequently sending and receiving instant messages at work will distract employees and reduce their work absorption and productivity. Therefore, enterprises should take measures to control employees' media multitasking behavior.

In addition, when studying the impact of using media for work or study on employees' work participation, it was found that using other computer software or mobile applications (such as readers, Word, Excel, etc.) to work or study will have a significant positive impact on work engagement. As a consequence, the enterprise should create a good working and learning atmosphere, improve the staff's work concentration, and then enhance the staff's work investment to create good benefits for the enterprise. Second, employees should reasonably allocate the time of daily media use and balance the relationship between life and Internet.

In the process of data statistics, it was found that the average daily media usage time of the respondents is 12.89 hours, which means that nearly half of the respondents spend on the Internet media in a day. Among them, it takes the most time to send and receive instant messages such as WeChat, QQ messages, SMS, emails, etc., with an average of 2.09 hours per day. Although the usage time of a single media is not too long, the total amount of media usage time of modern people is an issue that cannot be ignored. If the media is used for too long, it will inevitably lead to excessive psychological dependence on the media. Therefore, it is very important to learn to shift attention from the media and balance the relationship between life and the Internet.

\section{REFERENCES}

[1]Eyal Ophir, Clifford Nass, Anthony D. Wagner, Michael I. Posner, "Cognitive Control in Media Multitaskers", Proceedings of the National Academy of Sciences of the United States of America, Vol.106, pp. 15583 - 15587, 2009. DOI: http://www.pnas.org/cgi/doi/10.1073/pnas.0903620106

[2]Roberts, Donald F, "Generation M: Media in the Lives of 8- to 18-Year-Olds", Henry J. Kaiser Family Foundation, 2010

[3]Lang, A, Chrzan, "Media multitasking: Good, bad, or ugly?", Communication Yearbook, Vol.39, pp. 99-128, 2015, DOI:10.1080/23808985.2015.11679173

[4]Jeong, S.-H, Fishbein, M. "Predictors of multitasking with media: media factors and audience factors", Media Psychology, Vol.10, pp. 364-384, 2007, DOI:10.1080/15213260701532948

[5]Papper, R. A., Holmes, M. E., \& Popovich, M. N. "Middletown media studies: Media multitasking and how much people really use the media", The International Digital Media and Arts Association Journal, Vol.1(1), pp. 3-56. 2004

[6]Yeykelis, L., Cungs, J. J., \& Reeves, B. "Multitasking on a single device: Arousal and the frequency, anticipation, and prediction of switching 
between media content on a computer", Journal of Communication, Vol.64(1), pp. 167-192, 2014

[7]Annie Lang, "Limited Capacity Model of Motivated Mediated Message Processing”, pp. 193-204, 2017, DOI:

https://doi.org/10.1002/9781118783764.wbieme0077

[8]Chanjuan Xia, "The impact of media multitasking and social networking site use on cognitive ability", Huazhong Normal University, MA thesis, 2014 (In Chinese)

[9]Yiwei Wang, "Research on the Media Multi-task Behavior of College Students in the Learning Context", Huazhong Normal University, MA thesis, 2015 (In Chinese)

[10]Jingjun Chen, Huiyi Lin, Xingyi Liao, "Will media multitasking have a negative impact on online learning - an experimental analysis of eighth grade students' learning mathematics video under different interference conditions", Modern educational technology, Vol.31, pp. 50-56, 2021, DOI:CNKI:SUN:XJJS.0.2021-03-008 (In Chinese)

[11]Xiaohui Yang, Xiaoqi Zhu, "Media multi task operation, personality and bad mood of College
Students", Chinese Journal of mental health, Vol.28, pp. 277-282, 2014, doi:10.1111/jcom.12070 (In Chinese)

[12]Wei Xu, "The influence of media multitasking on College Students' learning from the perspective of new media", Campus psychology, Vol.15, pp.407-410, 2017, DOI: 10.19521/j.cnki.1673-1662.2017.06.002 (In Chinese)

[13] Maslach C, Schaufeli W B, Leiter M P. “Job burnout”, Annual Review of Psychology, Vol.52, pp.397-422, 2001, DOI:

https://doi.org/10.1146/annurev.psych.52.1.397

[14] Wilmar B. Schaufeli, Marisa Salanova, Vicente González-romá, Arnold B. Bakker, "The Measurement of Engagement and Burnout: A Two Sample Confirmatory Factor Analytic Approach", Journal of Happiness Studies, Vol.3, 2002,

DOI:10.1023/A:1015630930326

[15] Chen Liu, "The influence of College Students' media multitasking behavior on the function of central executive system", Huazhong Normal University, MA thesis, 2015 (In Chinese) 